\title{
Ecological divergence of burying beetles into the forest canopy
}

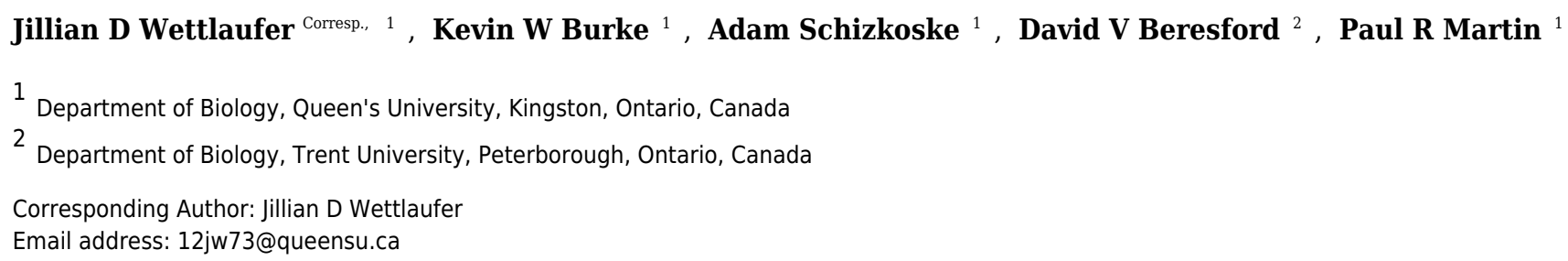

Closely related species with overlapping geographic ranges encounter a significant challenge: they share many ecological traits and preferences but must partition resources to coexist. In Ontario, potentially eleven species of carrion beetles (Coleoptera: Silphidae) live together and require vertebrate carrion for reproduction. Their reliance on an ephemeral and uncommon resource that is unpredictable in space and time is thought to create intense intra- and interspecific competition. Evidence suggests that burying beetle species reduce competition by partitioning carrion for breeding across different habitats, temperatures, and seasons. Here, we test predictions of an alternative axis for partitioning carrion: vertical partitioning between the ground and forest canopy. We conducted a survey of carrion beetles from May to July 2016 at the Queen's University Biological Station across 50 randomly generated points using baited lethal traps at $0 \mathrm{~m}$ and $6 \mathrm{~m}$. Ground traps yielded more species and individuals compared to those in the canopy, and the number of individuals and species caught increased through the season in both trap types. Ground and canopy traps were accurately distinguished by the presence or absence of three species: ground traps contained more Nicrophorus orbicollis and Necrophila americana, while canopy traps contained more Nicrophorus pustulatus. We trapped $253 \mathrm{~N}$. pustulatus in the canopy, but only 60 on the ground. N. pustulatus is thought to be rare across its geographic range, but our results suggest it is uniquely common in canopy habitats, demonstrating a vertical partitioning of habitat and resources. Our results are consistent with $N$. pustulatus having diverged into canopy habitats as a strategy to coexist with closely related sympatric species when competing for similar resources. We still, however, do not know the traits that allow $N$. pustulatus to flourish in the canopy, exactly how $N$. pustulatus uses canopy resources for breeding, or the factors that restrict the expansion of other burying beetles into this habitat. 
1 Ecological divergence of burying beetles into the forest canopy

2

3 Jillian D. Wettlaufer ${ }^{1}$, Kevin W. Burke ${ }^{1}$, Adam Schizkoske ${ }^{1}$, David V. Beresford ${ }^{2}$, Paul R.

4 Martin $^{1}$.

5

$6{ }^{1}$ Department of Biology, Queen's University, Kingston, Ontario, Canada

$7 \quad{ }^{2}$ Department of Biology, Trent University, Peterborough, Ontario, Canada

8

9 Corresponding Author:

10 Jillian D. Wettlaufer ${ }^{1}$

11 Email address: 12jw73@queensu.ca 


\section{ABSTRACT}

Closely related species with overlapping geographic ranges encounter a significant challenge: they share many ecological traits and preferences but must partition resources to coexist. In Ontario, potentially eleven species of carrion beetles (Coleoptera: Silphidae) live together and require vertebrate carrion for reproduction. Their reliance on an ephemeral and uncommon resource that is unpredictable in space and time is thought to create intense intra- and interspecific competition. Evidence suggests that burying beetle species reduce competition by partitioning carrion for breeding across different habitats, temperatures, and seasons. Here, we test predictions of an alternative axis for partitioning carrion: vertical partitioning between the ground and forest canopy. We conducted a survey of carrion beetles from May to July 2016 at the Queen's University Biological Station across 50 randomly generated points using baited lethal traps at $0 \mathrm{~m}$ and $6 \mathrm{~m}$. Ground traps yielded more species and individuals compared to those in the canopy, and the number of individuals and species caught increased through the season in both trap types. Ground and canopy traps were accurately distinguished by the presence or absence of three species: ground traps contained more Nicrophorus orbicollis and Necrophila americana, while canopy traps contained more Nicrophorus pustulatus. We trapped $253 N$. pustulatus in the canopy, but only 60 on the ground. N. pustulatus is thought to be rare across its geographic range, but our results suggest it is uniquely common in canopy habitats, demonstrating a vertical partitioning of habitat and resources. Our results are consistent with $N$. pustulatus having diverged into canopy habitats as a strategy to coexist with closely related sympatric species when competing for similar resources. We still, however, do not know the traits that allow N. pustulatus to flourish in the canopy, exactly how N. pustulatus uses canopy resources for breeding, or the factors that restrict the expansion of other burying beetles into this habitat. 


\section{INTRODUCTION}

The coexistence of closely related species presents an ecological challenge: they share many traits and preferences through recent common ancestry and often depend on similar resources, and yet are thought to require ecological partitioning to allow them to coexist (Weber \& Strauss, 2016). For this reason, burying beetles in the family Silphidae have been a focus of ecological studies of resource partitioning - they all require vertebrate carcasses for reproduction and these carcasses are thought to be limiting resources in their environment (Wilson, Knollenberg, \& Fudge, 1984; Anderson \& Peck, 1985; Trumbo \& Bloch, 2002). Despite these similar requirements, many different Silphid species co-occur within communities, sometimes fighting over the same resources (Wilson, Knollenberg \& Fudge, 1984; Otronen, 1988; Trumbo $\&$ Bloch, 2002). Do these species partition carrion to coexist within communities, and, if so, how? Previous studies have suggested an answer to this question: burying beetles may coexist because they partition carrion based on habitat, timing of seasonal activity and breeding, timing of diel activity, and trade-offs between the ability to locate carcasses quickly versus competitive dominance (Anderson, 1982; Wilson, Knollenberg \& Fudge, 1984; Trumbo, 1990; Trumbo \& Bloch, 1992; Benigner \& Peck, 1992; Lingafelter, 1995; Trumbo \& Bloch, 2000; Trumbo \& Bloch, 2002; Urbanski \& Baraniak, 2015). These axes of ecological partitioning are plausible hypotheses to explain how different burying beetle species coexist, but the ecological distinctions of some species remain poorly known.

The ecology of one species in particular, Nicrophorus pustulatus, remains enigmatic. Historically, N. pustulatus was found to be widespread but rare across its range because few individuals were caught in ground traps typically set for burying beetles (Anderson \& Peck, 1985). However, the regular occurrence of N. pustulatus at lights (Anderson, 1982; Lingafelter, 
59

60

61

62

63

64

65

66

67

68

69

70

71

72

73

74

75

76

77

78

79

80

81

1995) was difficult to explain. A later discovery of N. pustulatus feeding on gray ratsnake

(Pantherophis spiloides) eggs (Blouin-Demers \& Weatherhead, 2000; Keller \& Heske, 2001) led

some researchers to suggest that $N$. pustulatus specialized on ratsnake eggs, or oviparous snake

eggs in general; this idea was supported by an observation of $N$. pustulatus larvae feeding on

northern ringneck snake (Diadophis punctas edwardsii) eggs (Legros, Pratt \& Beresford, 2010)

and an unpublished report of them feeding on eastern fox snake (Pantherophis gloydi) eggs

(Brown \& Beresford, 2016). However, the range of N. pustulatus extends beyond that of

oviparous snakes (Anderson \& Peck, 1985), and its occurrence in a failed Northern Saw-whet

Owl (Aegolius acadicus) nest 8m high in the forest canopy in Connecticut, USA was inconsistent with $N$. pustulatus specializing on snake eggs (Philips, Root \& DeSimone, 1983). The use of vertebrate carrion by N. pustulatus in captivity (Robertson, 1992; Trumbo, 1992; Rauter \& Moore, 2002; Trumbo, 2007; Rauter \& Rust, 2012) also suggested that this species might use vertebrate carrion in nature similar to other Nicrophorus species.

Further studies have reported N. pustulatus to be more common in the forest subcanopy

and canopy, rather than on the ground where most Nicrophorus species breed and feed. $N$.

pustulatus was first caught in the canopy in general insect traps (e.g. flight intercept traps;

Ulyshen \& Hanula, 2007). Following this work, burying beetle surveys using baited traps found

N. pustulatus almost exclusively several metres above the ground (Ulyshen, Hanula \& Horn, 2007; LeGros \& Beresford, 2010). These canopy N. pustulatus would have gone undetected using ground-based surveys, such as carrion baited pit-fall traps (Su \& Woods, 2001; Schroeder, Buddle \& Saint-Germaine, 2009), that were typically used because burying beetles were thought to require ground soil for burying and reproduction. To date, five studies have used baited traps to sample burying beetles in the canopy, and all have detected N. pustulatus. Ulyshen, Hanula 
82 and Horn (2007) discovered N. pustulatus was more abundant in canopy traps, where 33

83 individuals were found at $5 \mathrm{~m}$ and $15 \mathrm{~m}$, and only 1 individual was caught at $0.5 \mathrm{~m}$ above the

84 ground. LeGros and Beresford (2010) found N. pustulatus also preferred canopy habitats, where

856 individuals were caught in $6 \mathrm{~m}$ traps and none at $2 \mathrm{~m}$ and $4 \mathrm{~m}$. Lowe and Lauff (2012)

86 investigated arboreal carrion use by suspending baited nest boxes $9-10 \mathrm{~m}$ in the canopy and found

$87 N$. pustulatus on 6 occasions (with no observations of reproductive behaviour), representing

88 fewer than $4 \%$ of beetle encounters with carrion in their study. Dyer and Price (2013) collected

89106 individuals at $2.5 \mathrm{~m}$ compared to 47 individuals at $0.5 \mathrm{~m}$ in surveys in Maryland, USA.

90 Brown and Beresford (2016) collected perhaps the greatest number of N. pustulatus; they

91 captured 174 individuals in $6 \mathrm{~m}$ traps, representing $13.3 \%$ of their total Nicrophorus catch, in

92 Thousands Islands National Park, Ontario and Brockville, Ontario. Overall, N. pustulatus has

93 been repeatedly caught in elevated traps, but only rarely in large numbers.

94 Here, we test the hypothesis that Nicrophorus pustulatus is primarily found in the

95

canopy, and that the burying beetle community differs in species occurrence and abundance

between the ground and the canopy. To test these hypotheses, we employed paired, baited traps on the ground and $6 \mathrm{~m}$ off the ground at our study site in southeastern Ontario, Canada. Because burying beetles typically breed on the ground (Anderson \& Peck, 1985), we predicted that (1) traps on the ground would yield more species and individuals compared to those in the canopy, (2) ground and canopy traps would differ in their composition and abundance of species, and (3) canopy traps would collect a greater abundance of Nicrophorus pustulatus compared to ground traps. 
103

104

105

106

107

108

109

110

111

112

113

114

115

116

117

118

119

120

121

122

123

124

125

\section{METHODS}

\section{$\underline{\text { Study Species }}$}

The carrion beetle family, Silphidae, is comprised of two subfamilies: Silphinae and Nicrophorinae. Species in the subfamily Silphinae may avoid competition with Nicrophorinae species by using larger carcasses, whereas Nicrophorus prefer smaller carcasses that can be buried more easily (Anderson \& Peck, 1985). Nicrophorinae, also known as the burying beetles, exhibit unique resource guarding and parental care behaviour. Burying beetles breed on small vertebrate carcasses and typically avoid competition with flies and other scavengers by burying or covering the carcass (Anderson \& Peck, 1985). If more than one pair of adult beetles is present on the carcass, including pairs of different species, fighting typically ensues and continues until only one pair remains (Anderson \& Peck, 1985). The winning pair then rears and cares for their offspring, using the carcass to feed their larvae. In southeastern Ontario, potentially eleven species of carrion beetles (Anderson \& Peck, 1985) live closely together and compete for small vertebrate carrion. These carrion beetles show evidence of both spatial and temporal habitat partitioning (for details, see Anderson, 1982; Wilson, Knollenberg \& Fudge, 1984; Anderson \& Peck, 1985; Beninger \& Peck, 1992; Scott, 1998; Trumbo \& Bloch, 2000; Sikes, Trumbo, \& Peck, 2016).

We included all species of carrion beetles from the family Silphidae that we caught during our study. These species included six in the genus Nicrophorus (Nicrophorinae):

Nicrophorus orbicollis, N. pustulatus, N. tomentosus, N. sayi, N. defodiens, and N. hebes, and four species from the subfamily Silphinae: Necrophila americana, Necrodes surinamensis, Oiceoptoma inaequale, and O. noveboracense.

$\underline{\text { Study Site }}$ 
127 University Biology Station (QUBS, 44.5653, -76.322, 129m) properties near Elgin, Ontario,

128 Canada during the reproductive period from early May until late July 2016. We set traps at 50

129 block-randomized points across QUBS properties that are the subject of long-term studies of

130 diverse taxonomic groups (birds, plants and insects). These study points were originally chosen

131 by randomly selecting GPS points that fell within the property boundaries, with the restriction

132 that no point could fall within a body of water, and each point was at least 400m away from all

133 other points. Our study site includes areas of regrowth forest dominated by sugar maple (Acer

134 saccharum) and ironwood (Ostrya virginiana), with some species of ash (Fraximus spp.), elm

135 (Ulmus spp.), hickory (Carya spp.) and birch (Betula spp.), as well as basswood (Tilia

136 americana), and areas of mixed forest with coniferous trees (Pinus spp., Thuja occidentalis,

137 Tsuga canadensis) (Martin, 1994). The more mature deciduous and mixed forests reach an

138 average height of about $24 \mathrm{~m}$ (Jones et al., 2001). Additional trapping locations at our study site

139 include: areas of wet woodland composed mainly of eastern white cedar (Thuja occidentalis) and

140 birch species, man-made conifer plantations, edges of small lakes and beaver ponds, forest

141 edges, open fields that were once used for agriculture, or open rocky outcrops composed of

142 scattered red oak (Quercus rubra), eastern white pine (Pinus strobus), red (Juniperus virginia)

143 and common (J. communis) juniper, and a number of mosses, grasses, and lichen-covered rock

144 (Martin, 1994).

145 Trapping Methods

146 At each trapping location, we set two concurrent traps and collected them after 7 days: a

147 pitfall trap in the ground, and a trap of the same design suspended $6 \mathrm{~m}$ above ground. We

148 sampled each point twice: once in May/June, and once in July. We constructed our traps using 
149 plastic buckets approximately $35 \mathrm{~cm}$ deep and $17 \mathrm{~cm}$ in diameter. We filled the buckets with $6 \mathrm{~cm}$

150 (depth) of saturated saline solution to kill and preserve the beetles. We covered the top of each

151 trap with a $35 \mathrm{~cm}^{2}$ piece of chicken wire. We baited each trap with one chicken wing wrapped in

152 cheesecloth, suspended from the middle of the chicken wire using steel craft wire. The bait was

153 frozen until deployed in traps without any prior thawing or ripening and suspended above the

154 saline preservative. We covered each trap with a $30 \mathrm{~cm}^{2}$ plywood board to prevent rainwater from

155 entering. We secured each ground trap by placing large rocks from each site on top of the

156 plywood board in an attempt to deter vertebrate scavengers from disrupting the traps. Canopy

157 traps were hung $6 \mathrm{~m}$ high in tree branches; the exact distance between the paired ground and

158 canopy traps varied depending on the availability of soil for ground pitfall traps and trees for

159 canopy traps (average $=4.8 \mathrm{~m}$ between paired ground and canopy traps with the largest distance

160 being $<20 \mathrm{~m}$ ). Differences in the number of successful traps between the ground and canopy

161 were caused by a greater disturbance of ground traps $(\mathrm{N}=34)$, likely by vertebrate scavengers

162 stealing the bait and/or pulling the trap from the ground. Three traps were also omitted because

163 of trap failure due to human error in deployment. A total of 34 traps, mostly in the canopy, were

164 successfully deployed and were undisturbed by vertebrates but did not collect any carrion

165 beetles. These traps were included in tests for differences in the number of beetles and number of

166 species between ground and canopy traps, but were omitted from subsequent classification

167 analyses because they provided no information on carrion beetle community composition.

168 Species and Sex Identification

169 Each beetle specimen was first identified as a Silphidae by their relatively large size, possession

170 of clavate or capitate 11-segmented antennae, prominent fore coxae, and elytra that were 
171 truncate, tricostate, or lacking costae. Once identified as a Silphidae, each specimen was

172 identified to genus, species, and sex following Anderson \& Peck (1985).

173 Statistical Analyses

174 We performed all of our statistical analyses and plotting in R (R Core Team, 2016; version 175 3.3.1).

\section{Generalized Linear Mixed-effects Models}

To test our hypotheses that the number of species and abundance of burying beetles was higher in ground versus canopy traps, we ran generalized linear mixed-effects models with the number of species and total number of burying beetles as the response variables in two different models, and ground versus canopy trap and Julian date of trap retrieval as predictor variables in a saturated model. We included trapping location (station) as a random factor in each model because sampling events at the same location on different days were not independent from each other. We omitted traps that showed any evidence of disturbance, likely by vertebrate scavengers. We transformed the number of beetles $[\log ($ number of beetles +3$)]$ and rounded values to integers to meet the assumptions of the models. We rescaled Julian date using the rescale function in the R package arm (version 1.9-3; Gelman et al., 2016), that subtracts the mean and divides by 2 standard deviations, following recommendations in Bolker et al. (2009).

We first ran models with a Poisson distribution using the glmer function in the lme 4 package (version 1.1-12; Bates et al., 2016). We ran the full model for each response variable independently and examined its fit by plotting standardized residuals against fitted values and all predictors, testing for linearity and homogeneity in the variance of residuals for each predictor using plots and Bartlett's tests, testing if the distribution of residuals and predictors differed from normal using Shapiro-Wilk tests, and testing for overdispersion (Zuur et al., 2009). Poisson 
194 models for the number of beetles fit well. Poisson models for the number of species, however,

195 showed non-normal residuals, so we moved to Gaussian generalized linear mixed-effects models

196 using the lme function in the nlme package (version 3.1-128; Pinheiro et al., 2016). We checked

197 model fit of the Gaussian models as before (omitting tests of overdispersion) (Zuur et al., 2009).

198 We compared the performance of models with all combinations of predictor variables

199 using the dredge command in the MuMIn package (version 1.15.6; Bartoń, 2016) to determine

200 the best-performing model as assessed by Akaike information criterion values, controlling for

201 small sample size (AICc; lowest value indicating the best-performing model). We checked the fit

202 of our best-performing models using the same approach as our full models. We present the

203 results of our best-performing models (lowest AICc values) in this paper.

\section{Random Forest Models}

To test our hypotheses that burying beetle community composition differed between the ground and the canopy, and that $N$. pustulatus was only prevalent in the canopy, we first took a machine learning approach. Specifically, we used Random Forest classification models in the randomForest package in $\mathrm{R}$ (Breiman, 2001; version 4.6-12; Breiman et al., 2015). Random

Forest models combine many classification trees to identify which variables most accurately discriminate between groups (Cutler et al. 2007). Random Forest is a powerful alternative to traditional parametric and semiparametric statistical methods for classification and discrimination because it makes no distributional assumptions about the data (Cutler et al.,

213 2007), and can easily accommodate non-linear relationships that are common in nature (Friedl \& 214 Brodley, 1997). The Random Forest algorithm selects a random subset of the data 215 (approximately 63\%) and fits a classification tree to each subsample (Cutler et al., 2007). The 216 accuracy of each classification tree is then assessed using the remaining (unselected or "out-of- 
217 the-bag") portion of the data (Cutler et al., 2007). The out-of-the-bag data provide independent

218 estimates of classification accuracy because they were not used to fit the classification tree

219 (Cutler et al., 2007). Each classification tree uses only a small number of predictor variables at a

220 time; we identified the optimal number of predictor variables for classification as the smallest

221 number that yielded the lowest out-of-bag estimate of error rate. After many iterations of the

222 model (10,000 in our case), the Random Forest model provided an overall best classification

223 error rate, an error rate specific to each group, the relative importance of each predictor variable

224 for accurate classification, and other details such as the classification error rate for each

225 individual data point (Breiman, 2001). We chose to use Random Forest, rather than more recent

226 classification approaches (e.g., Hothorn et al., 2017), because Random Forest provided more

227 intuitive output and plots, and our analysis was relatively simple (bivariate classification, all

228 continuous predictors using the same scale) and thus did not suffer from some of the limitations

229 of the Random Forest approach (Strobl et al., 2007).

230 In our Random Forest models, we used trap height classification as the response (group)

231 variable and the average number of carrion beetles of each species collected at each survey point

232 (averaged across surveys) as the predictor variables. We omitted traps when no beetles were

233 caught, regardless of trap disturbance, because traps with zero beetles provided no information

234 on burying beetle community composition. We calculated the classification accuracy as 1 - out-

235 of-bag error rate and ran each model 10,000 times to obtain an average classification accuracy

236 with $95 \%$ confidence intervals. We constructed variable importance plots to show the relative

237 importance of all predictor variables for accurate classification in our model. We also used

238 partial dependence plots to depict the effects of our most important predictor variables on the

239 probability of correct classification (Cutler et al., 2007). 


\section{Binomial Generalized Linear Models}

241

We also tested our hypothesis that the occurrence and abundance of different beetle

242 species predicted ground versus canopy traps using a binomial generalized linear model (i.e.

243 logistic regression). Trap (ground=0, canopy=1) was the response variable, and different species'

244 average abundances (averaged across all surveys per site) were the predictor variables. We first

245 ran a model with all species included separately, with no interaction terms, and checked the fit of

246 the model using the heatmap.fit command in the R package heatmapFit (version 2.0.4; Esarey \&

247 Pierce, 2016). We then compared the performance of different models with all combinations of

248 predictor variables to identify the model that performed best (lowest AICc values) using the

249 dredge command in the MuMIn package (version 1.15.6; Bartoń, 2016). Perfect separation in our

250 best-performing model led to inflated and inaccurate statistical results. Thus, we used Firth's

251 penalized-likelihood logistic regression models to estimate coefficients and statistical results for

252 reporting.

253 Our raw data and R code files are available in the supplemental materials. 


\section{RESULTS}

255 Ground traps caught significantly more beetles compared to canopy traps (Poisson glmm, $256 z=11.49, P<0.0001$; Fig. 1), and the number of beetles caught in both ground and canopy traps 257 increased with Julian date (Poisson glmm, $z=5.32, P<0.0001$; Fig. 1). Ground traps also caught

258 significantly more species of burying beetles compared to canopy traps (Gaussian glmm, $t=8.82$, $259 P<0.0001$; Fig. 2), and the number of species in both ground and canopy traps increased with 260 Julian date (Gaussian glmm, $t=6.21, P<0.0001$; Fig. 2).

261 Ground and canopy traps also differed in the numbers and identities of species caught

262 (Table 1, Figs. 3, 4). Our most accurate Random Forest model correctly classified trap location 263 as ground or canopy $92.94 \%$ of the time [95\% Confidence Intervals (CI): 92.85- 93.03]. Model 264 accuracy was similar for ground and canopy traps; ground traps were classified correctly $91.11 \%$ 265 of the time (CI: $91.02-91.20 ; N=45$ sites), while canopy traps were classified correctly $95.00 \%$ 266 of the time (CI: $94.95-95.05 ; N=40$ sites). The presence and abundance of three species of carrion beetles were the most important predictors of trap height (Figs. 4-6). The presence of Nicrophorus orbicollis and, particularly, Necrophila americana, were the best predictors of ground traps (Fig. 5), and the likelihood of a trap being on the ground increased as abundance of both species increased (Fig. 6). The

271 presence, and increased numbers, of Nicrophorus pustulatus individuals was the best predictor of canopy traps (Figs. 5, 6). The abundance of other species also helped to accurately classify trap height, but to a lesser extent (Figs. 4, 5), and including them reduced classification accuracy relative to some simpler models. For example, our Random Forest classification model rerun with only Necrophila americana, Nicrophorus pustulatus, and Nicrophorus orbicollis correctly

276 classified trap location as ground or canopy $94.12 \%$ of the time, while our model rerun with only 
277 Necrophila americana and Nicrophorus pustulatus accurately classified trap location $85.88 \%$ of

278 the time; the full model (all species included) had a classification accuracy of $92.94 \%$.

279 Results from our binomial generalized linear models supported our Random Forest

280 analysis. The presence and abundance of Necrophila americana and Nicrophorus pustulatus

281 were the most statistically significant predictors of ground versus canopy traps in our best-

282 performing model (lowest AICc; Table 2). The presence and abundance of other species of

283 burying beetle were also significant predictors of ground versus canopy traps; however, the error

284 associated with their effect sizes was larger (Table 2), suggesting they were less consistent

285 predictors. The coefficient estimates for Nicrophorus pustulatus were very different from all

286 other species (Table 2), illustrating that N. pustulatus was uniquely common in the canopy and

287 rare on the ground (cf. Fig. 4). 


\section{DISCUSSION}

289

290

291

292

293

294

295

296

297

298

299

300

301

302

303

304

305

306

307

308

309

The abundance and occurrence of burying beetle species differed between ground and canopy traps. Ground traps captured more species and more individuals of burying beetles than canopy traps. The number of individuals and species increased as the season progressed from May to June, for both ground and canopy traps, indicating that there is a greater abundance and greater species diversity later in the season. Trap height classification of ground versus canopy traps differed with species present in the trap. Our most accurate Random Forest model for classifying trap height was very accurate (92.94\% classification accuracy), indicating there were repeatable differences between ground and canopy trap heights in the species that were caught.

Ground traps were accurately predicted by the abundance of either Necrophila americana or Nicrophorus orbicollis, and greater abundances of either of these species indicated the trap was more likely to be on the ground. Canopy traps were accurately predicted by the abundance of Nicrophorus pustulatus; the presence and increasing abundance of $N$. pustulatus in a trap was a strong predictor of canopy traps.

Our findings support previous studies that found greater abundances of $N$. pustulatus in elevated traps (Ulyshen \& Hanula, 2007; Legros \& Beresford, 2010; Dyer \& Price, 2013; Brown \& Beresford, 2016). N. pustulatus was historically thought to be rare, but widely distributed, in eastern North America (Anderson \& Peck, 1985), a pattern consistent with the few individuals caught in previous studies (Anderson, 1982; Robertson, 1992; LeGros \& Beresford, 2010; Brousseau, Cloutier \& Hébert, 2010). Our study supports the findings of Dyer and Price (2013), suggesting that $N$. pustulatus can be common, but only within the forest canopy. Ulyshen, Hanula, and Horn (2007) found 21 individuals of N. pustulatus in four $15 \mathrm{~m}$ canopy traps, and 
310 progressively fewer in the four $5 \mathrm{~m}$ traps $(\mathrm{N}=12)$ and in the four ground traps $(\mathrm{N}=1)$, suggesting

311 that $N$. pustulatus may be even more abundant at greater heights above our $6 \mathrm{~m}$ canopy traps.

The only known breeding resource for $N$. pustulatus in nature is snake eggs (Blouin-

313 Demers \& Weatherhead, 2000; Keller \& Heske, 2001; Smith et al., 2007; LeGros, Pratt \&

314 Beresford 2010). However, the geographic range of $N$. pustulatus extends beyond the range of all

315 oviparous snakes (Anderson \& Peck, 1985); thus, N. pustulatus must use other sources of food

316 for breeding in some parts of its range. In our study, we successfully baited N. pustulatus into

317 traps using chicken, and it has been reported that in a laboratory setting, $N$. pustulatus will

318 behave like a typical burying beetle and rear offspring on mice (Robertson, 1992; Trumbo, 1992;

319 Rauter \& Moore, 2002). Dyer and Price (2013) also trapped N. pustulatus using fish as bait, and

320 suggested that $N$. pustulatus might use fish as a resource for breeding, consistent with

321 observations of $N$. investigator (Hocking et al., 2006). Fish resources could be available in the

322 canopy in areas of fish-eating raptor nests (Dyer and Price, 2013). Philips, Root and DeSimone

323 (1983) discovered three adult $N$. pustulatus in a failed Northern Saw-whet Owl nest, supporting

324 the idea that this species uses other food for breeding beyond snake eggs. In addition, a pair of $N$.

325 pustulatus were observed and collected on dead Tree Swallow (Tachycineta bicolor) nestlings in

326 a failed nest at the Queen's University Biological Station, in a nest box approximately $1 \mathrm{~m}$ from

327 the ground (unpublished data; A. Schizkoske, 2016). Further studies are needed to determine the 328 typical food used for reproduction by N. pustulatus.

329 N. pustulatus may prefer canopy habitats to avoid intense competition for carrion on the

330 ground (Ulyshen, Hanula \& Horn, 2007) and to exploit important carrion resources in the

331 canopy. Carrion in the canopy may include squirrels (Sciuridae), birds, and bats (Chiroptera)

332 (LeGros \& Beresford, 2010). In particular, nesting squirrels and birds are common in the canopy 
333 and frequently experience mortality (Ricklefs, 1969), providing a reliable resource during the

334 peak breeding season (e.g., June at our study site for birds; Peck \& James, 1987; Keast, 1990;

335 Cadman et al., 2007). Furthermore, the breeding season of vertebrates in the canopy coincides

336 with the emergence of $N$. pustulatus at our study site (Trumbo, 1990).

337 Why don't other Nicrophorus species use canopy habitat given the abundance of nesting

338 vertebrates there? Nicrophorus beetles typically bury carcasses under soil or leaf litter to protect

339 them from other competitors and assist in reproduction (e.g., insulation). This burying behaviour

340 may not be possible in canopy habitats. The search for carrion in the canopy, including cavity

341 searching, may also be more energetically costly and some Nicrophorus species may be unable

342 to sustain flight for necessary periods or maneuver sufficiently to find carrion in this habitat. The

343 use of canopy habitats in Nicrophorus, however, may extend beyond N. pustulatus. Outside of $N$.

344 pustulatus' range, Okawara (1991) found that $N$. investigator and $N$. tenuipes were more

345 common in traps set at $9 \mathrm{~m}$ and $12.6 \mathrm{~m}$ than those set at $0 \mathrm{~m}, 1.8 \mathrm{~m}$, and $5.6 \mathrm{~m}$, suggesting that

346 vertical height partitioning may occur in Japanese (Hokkaido) carrion beetle communities as

347 well. While we still do not understand the constraints on using canopy habitat, the use of canopy

348 resources by $N$. pustulatus, and both $N$. investigator and $N$. tenuipes in Japan, suggests that

349 vertical height is another important axis of resource partitioning among closely related species of 350 burying beetles. 


\section{CONCLUSIONS}

352 Most species of carrion beetles in our study, and elsewhere, typically use carrion

353 resources located on the ground. N. pustulatus is an exception, primarily using carrion located in

354 canopy habitats and only secondarily using carrion on the ground. Our findings illustrate a

355 distinct vertical axis of resource partitioning in our carrion beetle community that may allow $N$.

356 pustulatus to co-occur with other closely related species that all require the same limited resource

357 for reproduction. 


\section{ACKNOWLEDGEMENTS}

360 We thank F. Bonier, D. Sikes, and two anonymous reviewers for providing helpful

361 comments and suggestions, and A. Colangelo for his help during the field season. We also thank

362 the Queen's University Biological Station staff and management. 
363

364

365

366

367

368

369

370

371

372

373

374

375

376

377

378

379

380

381

382

383

384

385

\section{LITERATURE CITED}

Anderson RS. 1982. Resource partitioning in the carrion beetle (Coleoptera: Silphidae) fauna of southern Ontario: ecological and evolutionary considerations. Canadian Journal of Zoology 60:1314-1325.

Anderson RS, Peck SB. 1985. The carrion beetles of Canada and Alaska. The Insects and Arachnids of Canada Part 13. Canadian Government Publishing Centre.

Bartoń K. 2016. MuMIn: Multi-Model Inference. R package version 1.15.6. https://CRAN.R-project.org/package=MuMIn

Bates D, Maechler M, Bolker B, Walker S, Christensen RHB, Singmann H, Dai B, Grothendieck G, Green P. 2016. lme4: linear mixed-effects models using 'Eigen' and S4. R package version 1.1-12.

Beninger CW, Peck SB. 1992. Temporal and spatial patterns of resource use among Nicrophorus carrion beetles (Coleoptera: Silphidae) in a Sphagnum bog and adjacent forest near Ottawa, Canada. The Canadian Entomologist 124:79-86.

Blouin-Demers G, Weatherhead PJ. 2000. A novel association between a beetle and a snake: parasitism of Elaphe obsoleta by Nicrophorus pustulatus. Écoscience 7:395-397.

Bolker BM, Brooks ME, Clark CJ, Geange SW, Poulsen JR, Stevens MHH, White J-SS. 2009. Generalized linear mixed models: a practical guide for ecology and evolution. Trends in Ecology and Evolution 24:127-135.

Breiman L. 2001. Random forests. Machine Learning 45:5-32.

Breiman L, Cutler A, Liaw A, Wiener M. 2015. Breiman and Cutler's random forests for classification and regression. $\mathrm{R}$ package version 4.6-12.

Brousseau P, Cloutier C, Hébert C. 2010. Selected beetle assemblages captured in pitfall 
386

387

388

389

390

391

392

393

394

395

396

397

398

399

400

401

402

403

404

405

406

407

408

traps baited with deer dung or meat in balsam fir and sugar maple forests of central Quebec. Environmental Entomology 39:1151-1158.

Brown MGC, Beresford DV. 2016. Unusually high trap catches of a snake egg parasitoid, Nicrophorus pustulatus (Coleoptera: Silphidae) in the Frontenac Axis population of gray ratsnake Pantherophis spiloides. Canadian Wildlife Biology \& Management 5:25-31

Cadman MD, Sutherland DA, Beck GG, Lepage D, Couturier AR (eds). 2007. Atlas of the breeding birds of Ontario, 2001-2005. Bird Studies Canada, Environment Canada, Ontario Field Orthinologists, Ontario Ministry of Natural Resources, and Ontario Nature, Toronto.

Cutler DR, Edwards Jr. TC, Beard KH, Cutler A, Hess KT. 2007. Random forests for classification in ecology. Ecology 88:2783-2792.

Dyer NW, Price DL. 2013. Notes on the diversity and foraging height of carrion beetles (Coleoptera: Silphidae) of the Nassawango Creek Preserve, Maryland, USA. The Coleopterists Bulletin 67:397-400.

Friedl M, Brodley C. 1997. Decision tree classification of land cover from remotely sensed data. Remote Sensing of Environment 61:399-409.

Gelman A, Su Y-S, Yajima M, Hill J, Pittau MG, Kerman J, Zheng T, Dorie V. 2016. arm: Data analysis using regression and multilevel/hierarchical models. R package version 1.93.

Hocking MD, Ring RA, Reimchen TE. 2006. Burying beetle Nicrophorus investigator reproduction on Pacific salmon carcasses. Ecological Entomology 31:5-12.

Hothorn T, Hornik K, Strobl C, Zeileis A. 2017. party: a laboratory for recursive partitioning. R package version 1.2-2. 
409 Jones J, DeBruyn RD, Barg JJ, Robertson RJ. 2001. Assessing the effects of natural

410 disturbance on a Neotropical migrant songbird. Ecology 82:2628-2635.

411 Keast A. 1990. Biogeography and ecology of forest bird communities. SPB Academic

412 Publishing.

413 Keller WL, Heske EJ. 2001. An observation of parasitism of black rat snake (Elaphe

414

415

obsolete) eggs by a burying beetle (Nicrophorus pustulatus) in Illinois. Transactions of Illinois State Academy of Science 94:167-169.

416

417

418

419

420

421

422

423

424

425

426

427

428

429

430

431

LeGros DL, Beresford DV. 2010. Aerial foraging and sexual dimorphism in burying beetles (Silphidae: Coleoptera) in a central Ontario forest. Journal of Entomological Society of Ontario 141:3-10.

LeGros DL, Pratt S, Beresford DV. 2010. Burying beetles as parasitoids of northern ringnecked snakes. International Reptile Conservation Foundation (IRCF), Reptiles \& Amphibians 17:234-235.

Lingafelter SW. 1995. Diversity, habitat preferences, and seasonality of Kansas carrion beetles (Coleoptera: Silphidae). Journal of Kansas Entomological Society 68:214-223.

Lowe AJ, Lauff RF. 2012. Arboreal burials in Nicrophorus spp. (Coleoptera: Silphidae). Psyche 2012:1-6.

Martin PR. 1994. Effects of forest management practices and forest-cutting history on the songbird communities of mature hardwood forest stands, Lake Opinicon, Leeds/Frontenac Cos., Ontario. Eastern Ontario Model Forest, Brockville, Ontario: Ontario Ministry of Natural Resources.

Okawara K. 1991. A note on height of fright in Nicrophorus [Silphidae] carrion beetles. Research Bulletins of the College Experiment Forests 48:463-467. 
432 Otronen M. 1988. The effect of body size on the outcome of fights in burying beetles

433 (Nicrophorus). Annales Zoologici Fennici 25:191-201.

434 Peck GK, James RD. 1987. Breeding birds of Ontario: nidiology and distribution v. 1.

435 Nonpasserines and v. 2. Passerines. The Royal Ontario Museum publications in Life

$436 \quad$ Sciences.

437 Philips JR, Root M, DeSimone P. 1983. Arthropods from a saw-whet owl (Aegolius

438 acadicus) nest in Connecticut. Entomological News 94:60-64.

439

440

441

442

443

444

445

446

447

448

449

450

451

452

453

454

Pinheiro J, Bates D, DebRoy S, Sarkar D, EISPACK authors, Heisterkamp S, Van Willigen B, R core team. 2016. $n l m e$ : linear and nonlinear mixed effects models. R package version 3.1-128.

R Core Team. 2016. $R$ : A language and environment for statistical computing. Version 3.3.1. (R Foundation for Statistical Computing, https://www.R-project.org/).

Rauter CM, Moore AJ. 2002. Quantitative genetics of growth and development time in the burying beetle Nicrophorus pustulatus in the presence and absence of post-hatching parental care. Evolution 56:96-110.

Rauter CM, Rust RL. 2012. Effect of population density on timing of oviposition and brood size reduction in the burying beetle Nicrophorus pustulatus Herschel (Coleoptera: Silphidae). Psyche 2012:437518. DOI:10.1155/2012/437518.

Ricklefs RE. 1969. An analysis of nesting mortality in birds. Smithsonian Contributions to Zoology Number 9: Smithsonian Institution Press.

Robertson IC. 1992. Relative abundance of Nicrophorus pustulatus (Coleoptera: Silphidae) in a burying beetle community, with notes on its reproductive behaviour. Psyche 99:189-190.

Schroeder B, Buddle CM, Saint-Germain M. 2009. Activity of flying beetles 
(Coleoptera) at two heights in canopy gaps and intact forests in a hardwood forest in Quebec. Canadian Entomologist 141:515-520.

457

458

459

460

461

462

463

464

465

466

467

468

469

470

471

472

473

474

475

476

477

Shubeck PP, Schleppnik AA. 1984. Silphids attracted to carrion near St. Louis, Missouri (Coleoptera: Silphidae). Kansas Entomological Society 57:360-362.

Sikes DS, Trumbo ST, Peck SB. 2016. Cryptic diversity in the New World burying beetle fauna: Nicrophorus hebes Kirby; new status as a resurrected name (Coleoptera: Silphidae: Nicrophorinae). Arthropod Systematics \& Phylogeny 74:299-309.

Smith G, Trumbo ST, Sikes DS, Scott MP, Smith RL. 2007. Host shift by the burying beetle, Nicrophorus pustulatus, a parasitoid of snake eggs. Journal of Evolutionary Biology 20:2389-2399.

Strobl C, Boulesteix A-L, Zeileis A, Hothorn T. 2007. Bias in random forest variable importance measures: illustrations, sources and a solution. BMC Bioinformatics 8:25.

Su JC, Woods SA. 2001. Importance of sampling along a vertical gradient to compare the insect fauna in managed forests. Environmental Entomology 30:400-408.

Trumbo ST. 1990. Reproductive success, phenology and biogeography of burying beetles (Silphidae, Nicrophorus). The American Midland Naturalist 124:1-11.

Trumbo ST. 1992. Monogamy to communal breeding: exploitation of a broad resource base by burying beetles (Nicrophorus). Ecological Entomology 17:289-298.

Trumbo ST, Bloch PL. 2000. Habitat fragmentation and burying beetle abundance and success. Journal of Insect Conservation 4:245-252.

Trumbo ST, Bloch PL. 2002. Competition between Nicrophorus orbicollis and N. defodiens: resource locating efficiency and temporal partitioning. Northeastern Naturalist 9:13-26.

Trumbo ST. 2007. Defending young biparentally: female risk-taking with and without a male in 
478

479

480

481

482

483

484

485

486

487

488

489

490

491

492

493

494

495

496

the burying beetle, Nicrophorus pustulatus. Behavioural Ecology and Sociobiology 61: 1717-1723.

Ulyshen MD, Hanula JL. 2007. A comparison of the beetle (Coleoptera) fauna captured at two heights above the ground in a North American temperate deciduous forest. The American Midland Naturalist Journal 158:260-278.

Ulyshen MD, Hanula JL, Horn S. 2007. Burying beetles (Coleoptera: Silphidae) in the forest canopy: The unusual case of Nicrophorus pustulatus Herschel. The Coleopterists Bulletin 61: 121-123.

Urbanski A, Baraniak E. 2015. Differences in early seasonal activity of three burying beetle species (Coleoptera: Silphidae: Nicrophorus F.) in Poland. The Coleopterists Bulletin 69: 283-292.

Weber MG, Strauss SY. 2016. Coexistence in close relatives: beyond competition and reproductive isolation in sister taxa. Annual Review of Ecology, Evolution, and Systematics 47:359-381.

Wilson DS, Knollenberg WG, Fudge J. 1984. Species packing and temperature dependent competition among burying beetles (Silphidae, Nicrophorus). Ecological Entomology 9:205-216.

Zuur AF, Ieno EN, Walker NJ, Saveliev AA, Smith GM. 2009. Mixed effects models and extensions in ecology with R. Springer, New York, NY, USA. 
Figure 1

Total number of beetles [log(total number of beetles +3$)$ ] for ground traps (blue) and canopy traps (red) by date with $95 \%$ confidence intervals (grey).

The abundance of beetles was higher in ground traps compared to canopy traps (generalized linear mixed-effects model, glmm, $P<0.0001)$, and the abundance of beetles increased with Julian date for both ground and canopy traps (glmm, $P<0.0001)$.

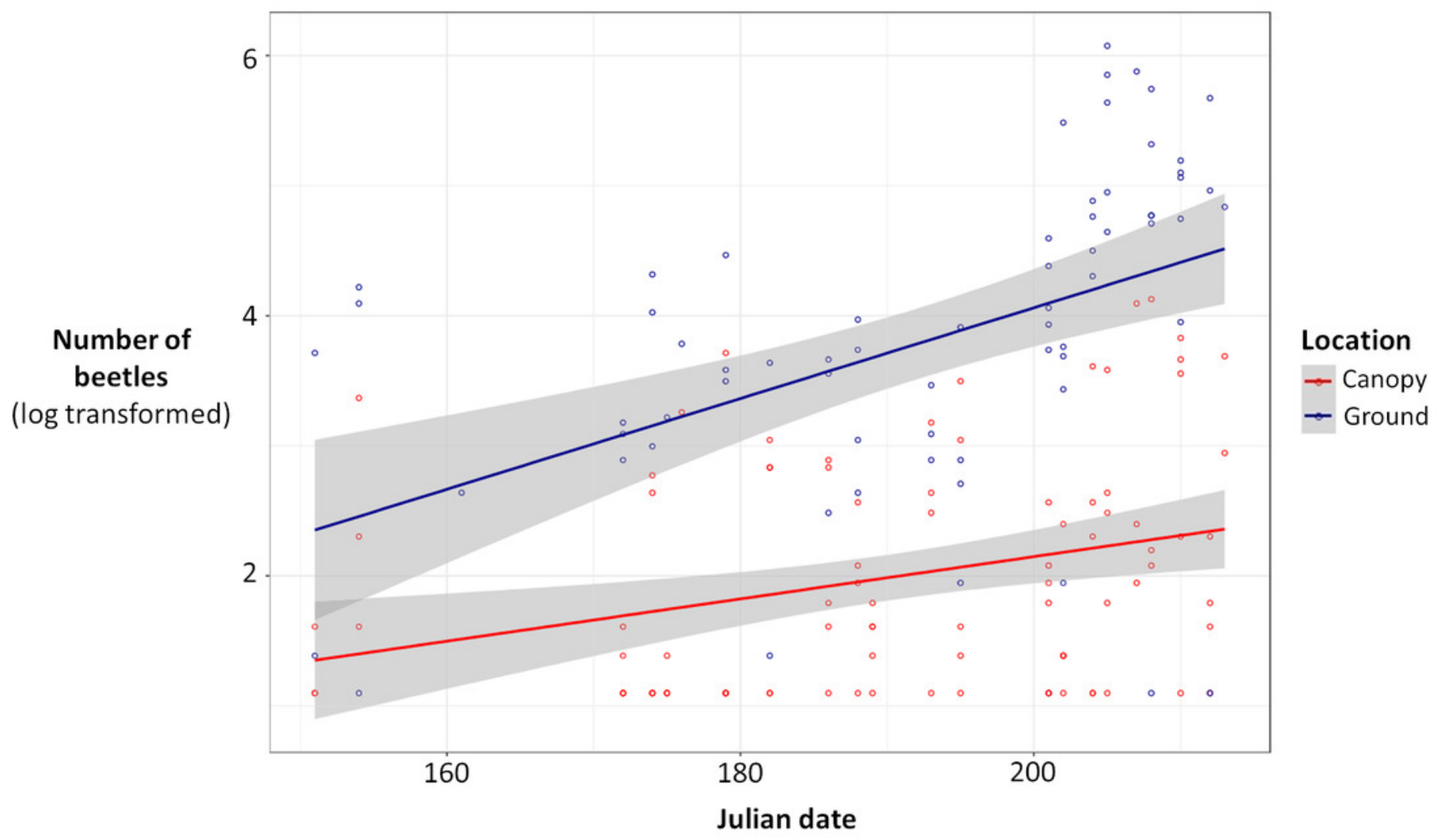


Figure 2

Number of species of beetles in ground traps (blue) compared to canopy traps (red) by Julian date with $95 \%$ confidence intervals (grey).

Ground traps contained more species than canopy traps ( $\mathrm{glmm}, P<0.0001)$, and the number of species caught increased with Julian date for both ground and canopy traps ( $\mathrm{glmm}$, $P<0.0001)$.

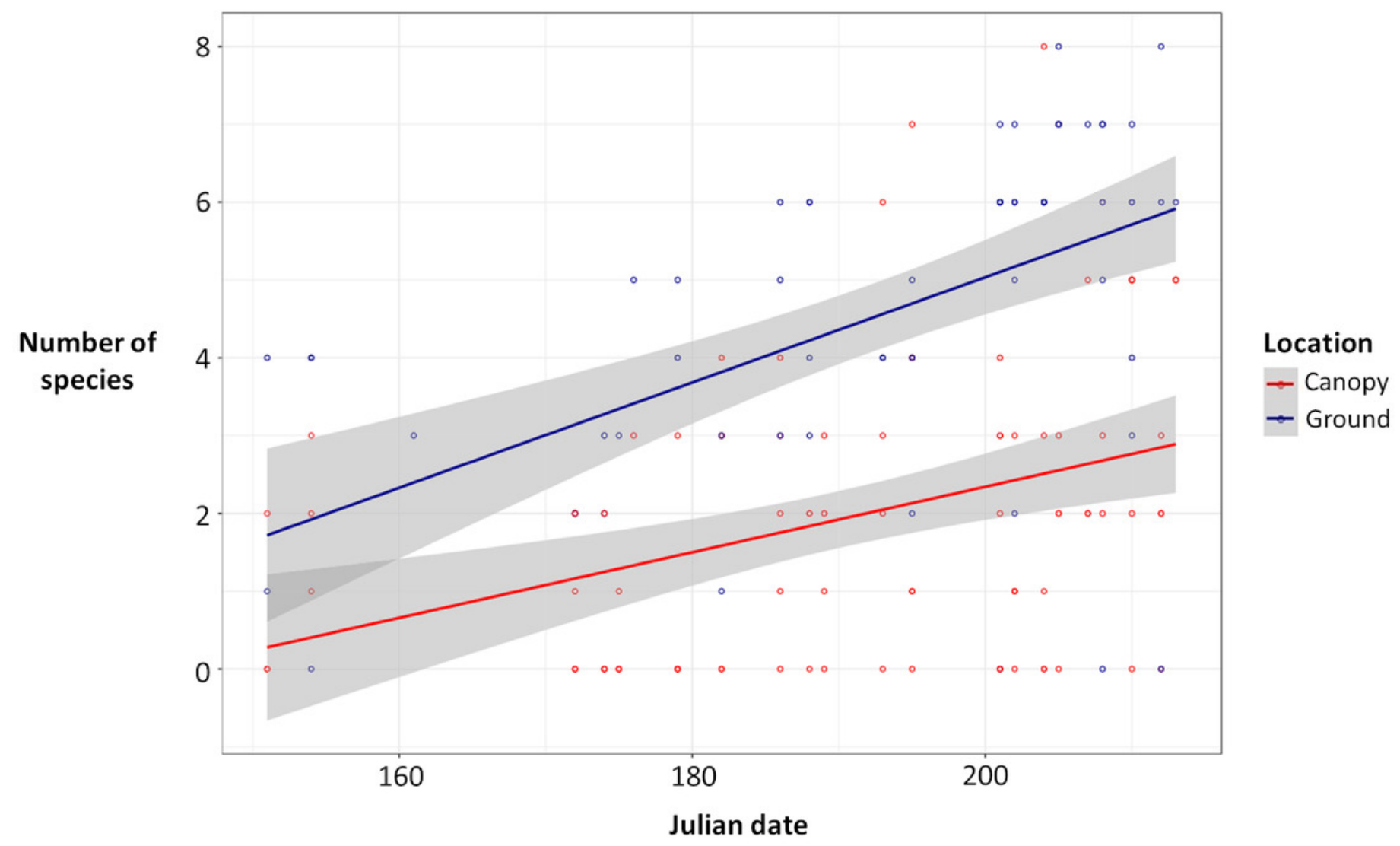




\section{Figure 3}

A) Total number of beetles (log transformed) for each species in canopy traps (white) vs. ground traps (grey). B) Difference between the total ground catch and the total canopy catch (log transformed)

A) Total number of beetles (log transformed) collected for each carrion beetle species in canopy traps (white) versus ground traps (grey). B) Difference between the total ground catch and the total canopy catch (log transformed) for each carrion beetle species, colour coded by genus. The number of beetles were log transformed because some species were extremely abundant while other species were rare. 
A

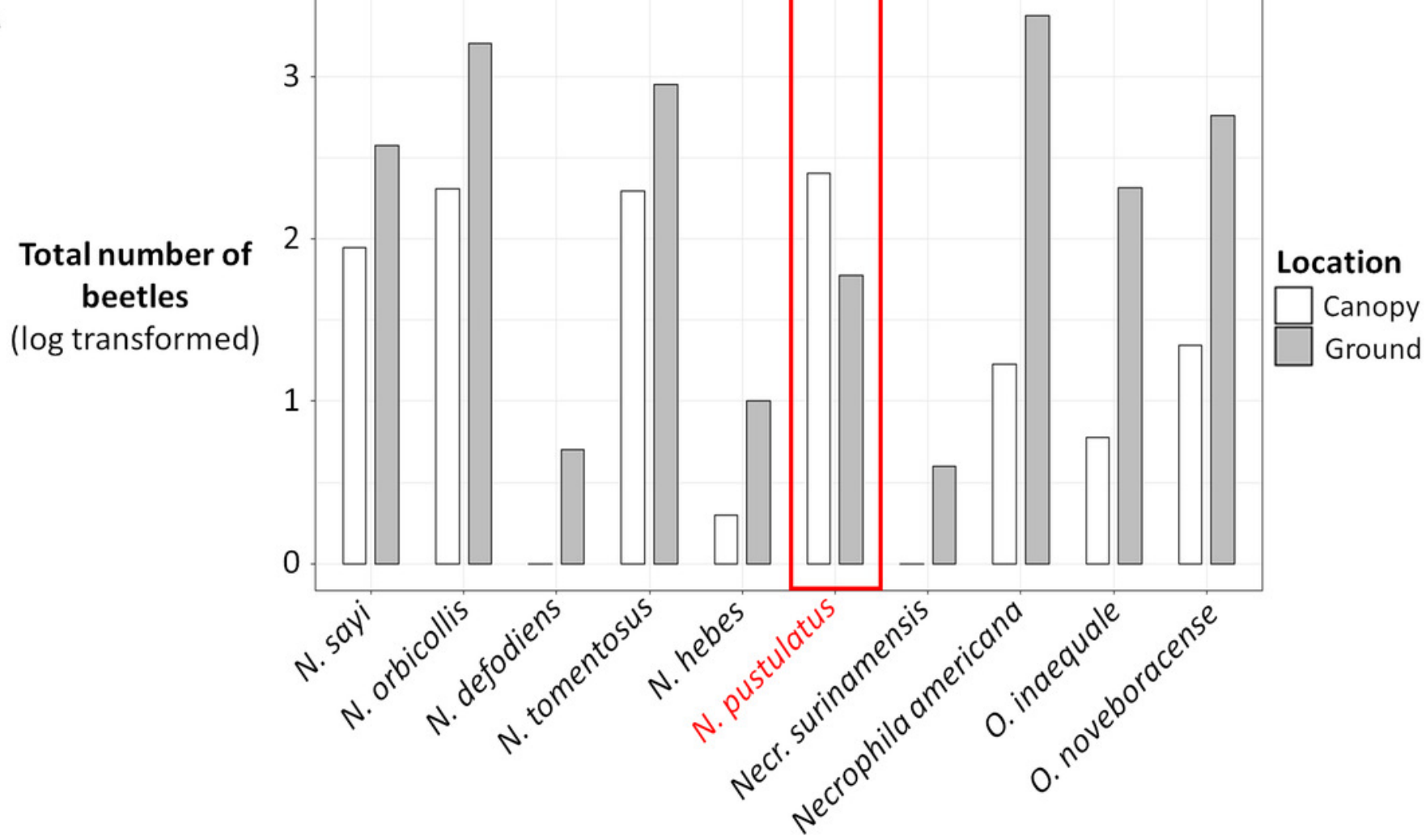

Species

B

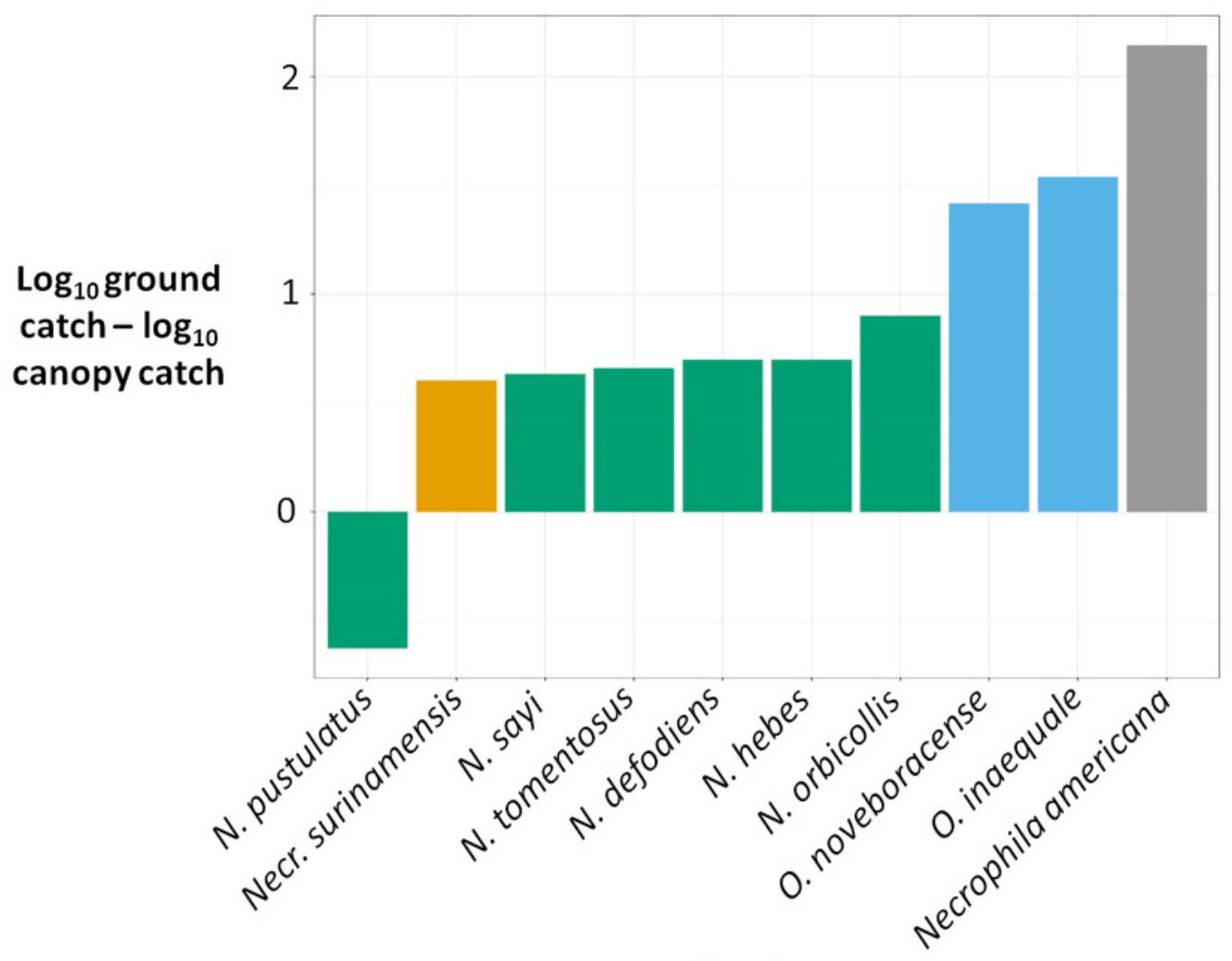

Genus

Necrodes Necrophila Nicrophorus Oiceoptoma

Species 
Figure 4

Log (number of beetles per trap +1 ) for each carrion beetle species collected in canopy traps (white) versus ground traps (grey).

The number of N. pustulatus per trap was higher in canopy traps compared to ground traps; all other burying beetle species were more common in ground traps. Boxplots show medians (thick lines), 25th and 75th percentiles (boxes), 1.5 times the interquartile range (whiskers), and outliers (points outside 1.5 times the interquartile range).

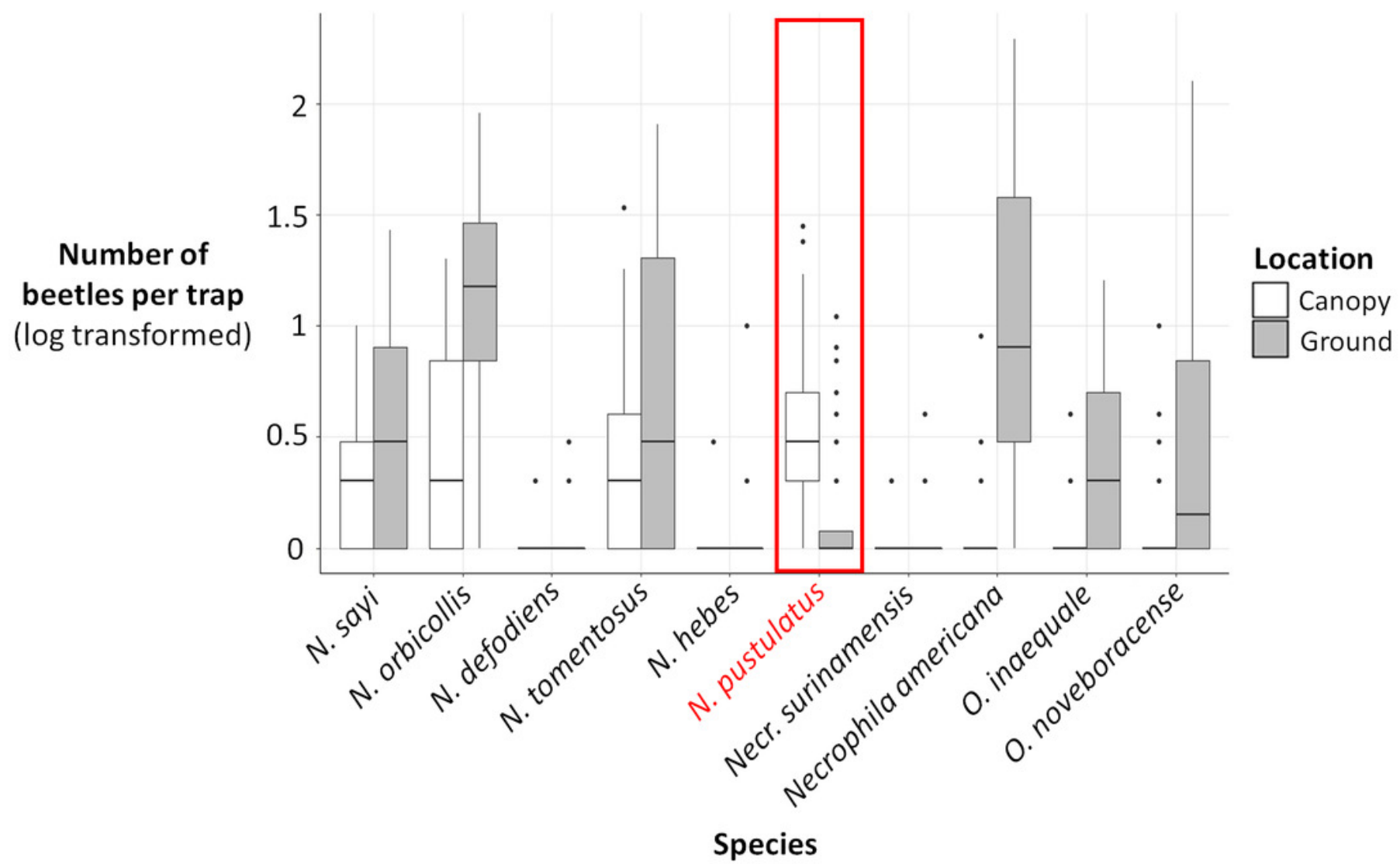




\section{Figure 5}

Variable importance plots for classification of ground versus canopy traps.

Variables that were important for classification were those that best predicted whether a trap was on the ground or in the canopy in our Random Forest classification model. Specifically, the relative accuracy in classification ( $x$-axis) compares the prediction error of the Random Forest model when applied to the portion of the dataset not used to fit the model (the "outof-bag" portion of the data); this error is calculated as the difference between the prediction error with predictor variables intact, and the prediction error after permuting each predictor variable in the out-of-bag portion of the dataset. The difference in prediction errors are averaged across all trees and normalized (divided by the standard deviation of the differences) to create the values in the $\mathrm{x}$-axis (Breiman et al., 2015). The best predictors of trap height were Necrophila americana, Nicrophorus pustulatus, and Nicrophorus orbicollis. 


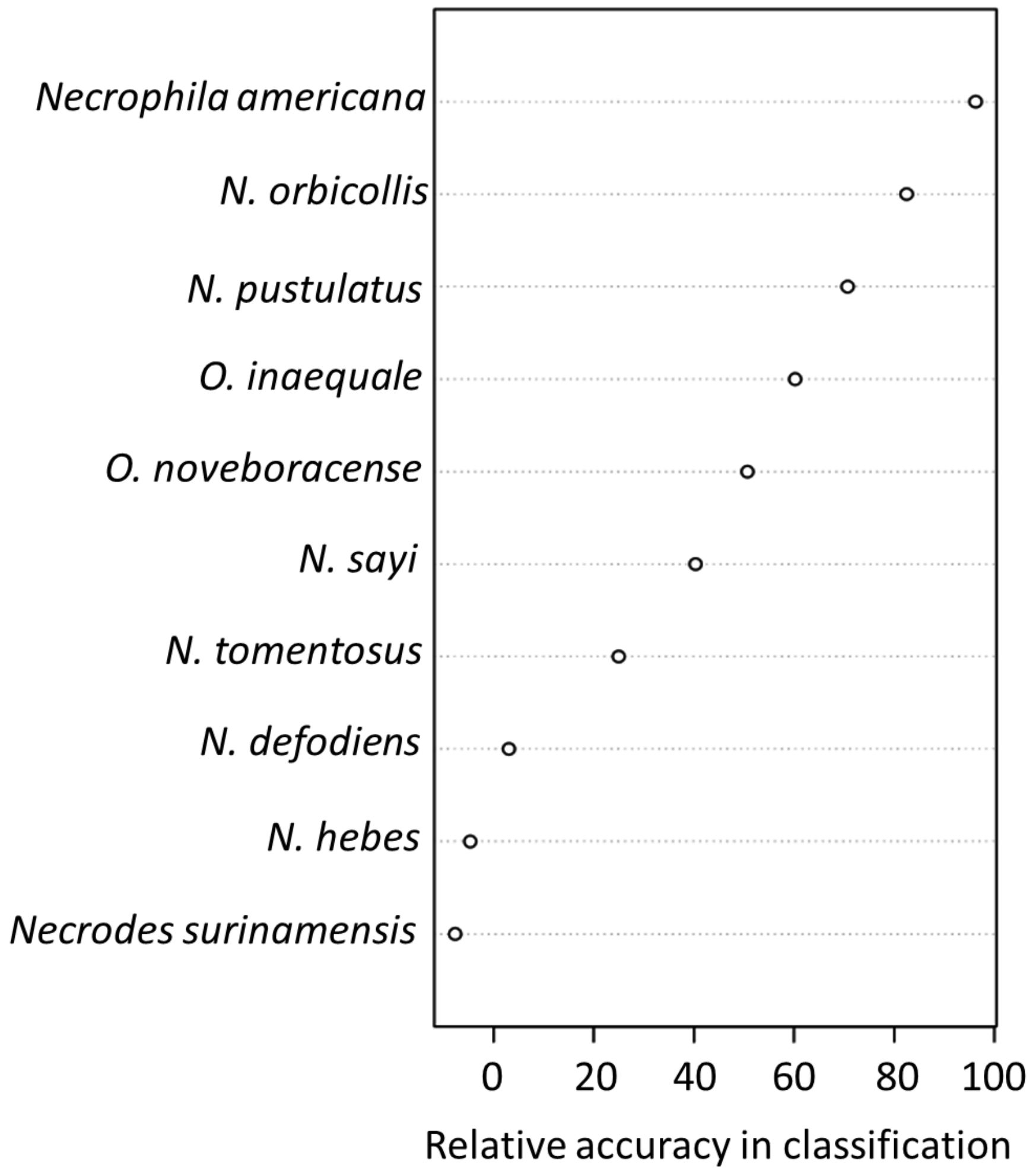




\section{Figure 6}

Partial dependency plots show the marginal effects of each species' abundance on the probability that a trap was in the canopy or on the ground.

The $y$-axis is the marginal effect on the classification probability of canopy traps (i.e., the relative logit contribution of the $\mathrm{x}$-axis variable on the probability of canopy traps for different values of the $x$-axis). A negative value means that the canopy traps are less likely than ground traps for that value of the $x$-axis; a positive value means that canopy traps are more likely. See Breiman et al. (2015) for details on calculations. Traps with more Necrophila americana (A) and Nicrophorus orbicollis (B) were more likely to be ground traps; traps with more Nicrophorus pustulatus (C) were more likely to be canopy traps. 
A

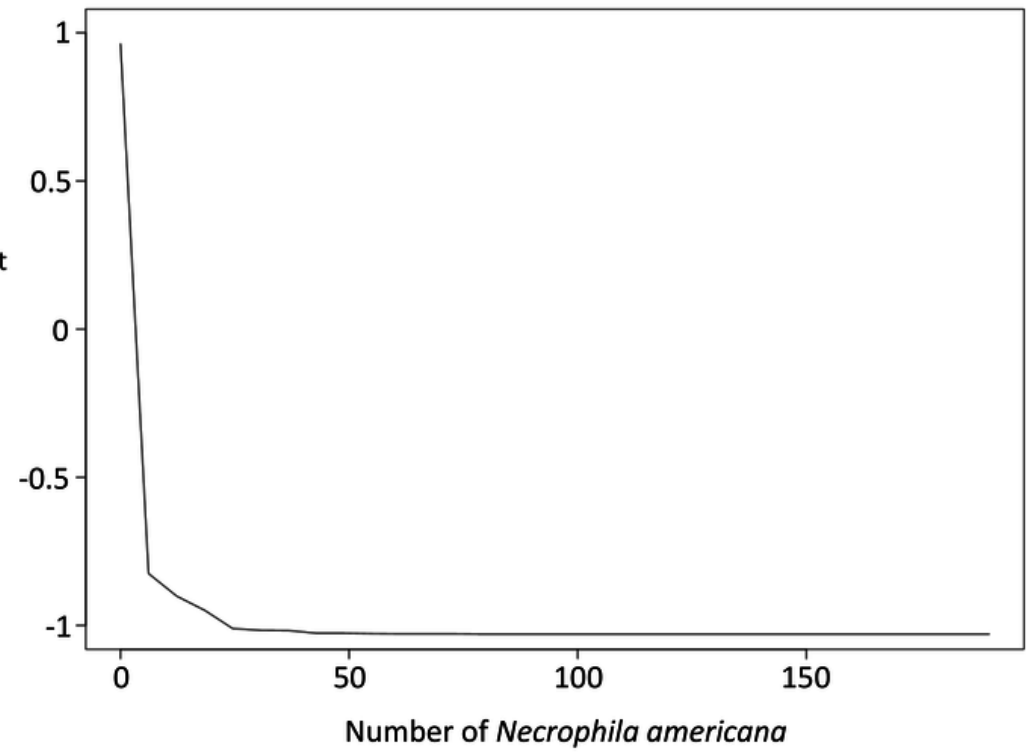

on the
Canopy

Ground classification probability of canopy traps

B

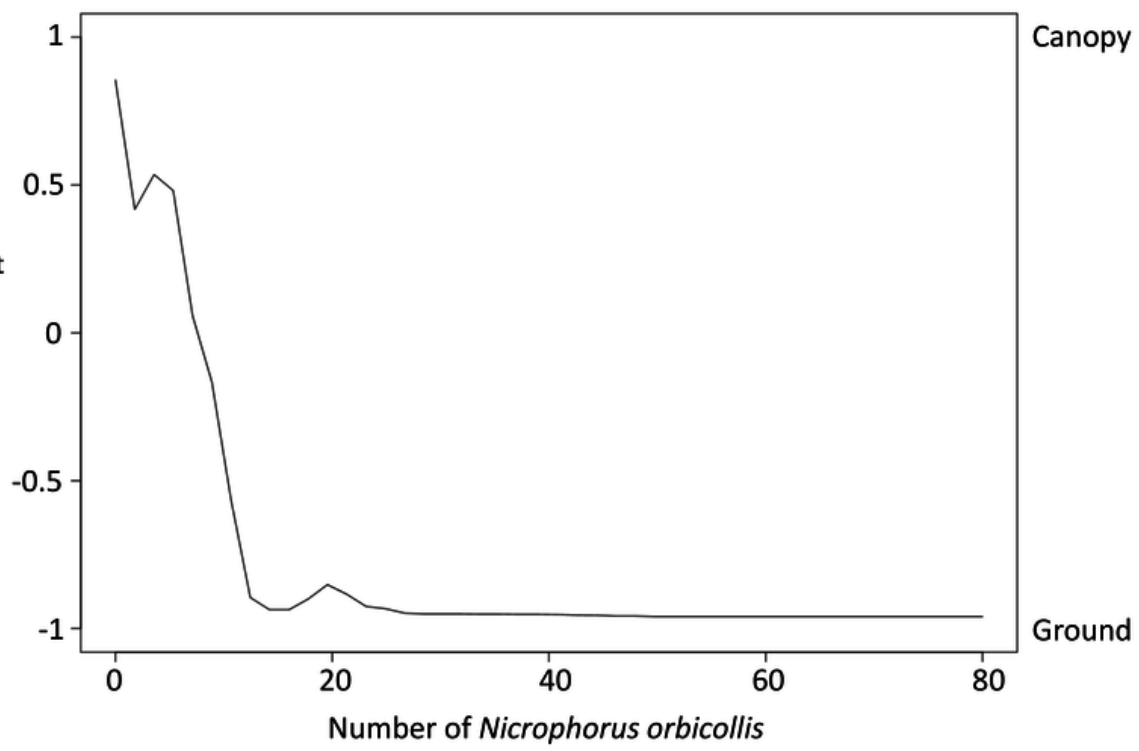

C

Marginal effect on the classification probability of canopy traps

Marginal effect on the classification probability of canopy traps

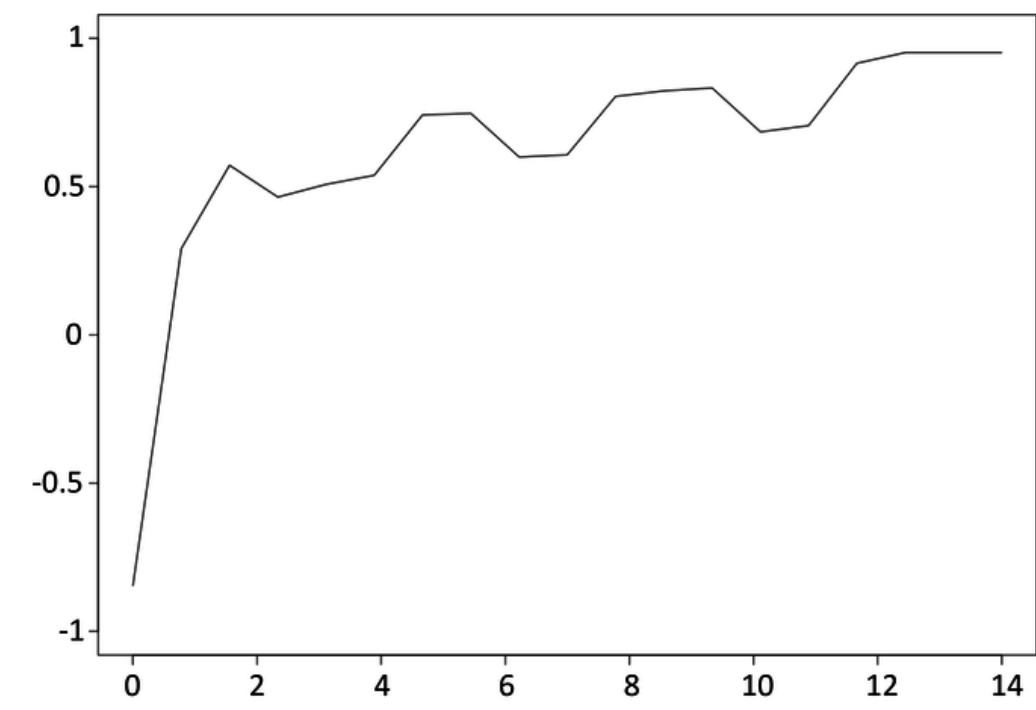

Canopy 


\section{Table $\mathbf{1}$ (on next page)}

Carrion beetles captured in ground and canopy traps at the Queen's University Biological Station (May-July 2016).

$\mathrm{N}$ reflects the total number of traps that caught beetles (traps that caught no beetles were removed). In total, 100 traps were set in both the canopy and on the ground. 


\begin{tabular}{|c|c|c|c|c|}
\hline \multirow{2}{*}{ Species } & \multicolumn{2}{|c|}{$\begin{array}{l}\text { Total number of beetles } \\
\text { by trap height }\end{array}$} & \multicolumn{2}{|c|}{$\begin{array}{l}\text { Number of traps with } \\
\text { each species present }\end{array}$} \\
\hline & $\begin{array}{l}\text { Ground }(0 \mathrm{~m}) \\
\mathrm{N}=80\end{array}$ & $\begin{array}{l}\text { Canopy }(6 \mathrm{~m}) \\
\mathrm{N}=65\end{array}$ & $\begin{array}{l}\text { Ground }(0 \mathrm{~m}) \\
\mathrm{N}=80\end{array}$ & $\begin{array}{l}\text { Canopy }(6 \mathrm{~m}) \\
\mathrm{N}=65\end{array}$ \\
\hline Nicrophorus orbicollis & 1609 & 203 & $74(92.5 \%)$ & $40(61.5 \%)$ \\
\hline Nicrophorus tomentosus & 902 & 198 & $47(58.8 \%)$ & $33(50.8 \%)$ \\
\hline Nicrophorus sayi & 378 & 88 & $54(67.5 \%)$ & $34(52.3 \%)$ \\
\hline Nicrophorus pustulatus & 60 & 253 & $20(25.0 \%)$ & $50(76.9 \%)$ \\
\hline Nicrophorus hebes & 10 & 2 & $2(2.5 \%)$ & $1(1.5 \%)$ \\
\hline Nicrophorus defodiens & 5 & 1 & $4(5.0 \%)$ & $1(1.5 \%)$ \\
\hline Necrophila americana & 2361 & 17 & $63(78.8 \%)$ & $8(12.3 \%)$ \\
\hline $\begin{array}{l}\text { Oiceoptoma } \\
\text { noveboracense }\end{array}$ & 574 & 22 & $40(50.0 \%)$ & $9(13.8 \%)$ \\
\hline Oiceoptoma inaequale & 207 & 6 & $47(58.8 \%)$ & $4(6.2 \%)$ \\
\hline Necrodes surinamensis & 4 & 1 & $2(2.5 \%)$ & $1(1.5 \%)$ \\
\hline Total & 6110 & 791 & & \\
\hline Total Nicrophorus & 2964 & 745 & & \\
\hline
\end{tabular}




\section{Table 2 (on next page)}

Results of Firth's penalized-likelihood logistic regression testing the hypothesis that the abundance of each carrion beetle species differed between ground and canopy traps ( $N=145$ comparisons).

The model represents the best-performing logistic regression model (lowest AICC value), comparing models with all possible combinations of predictor variables. 


\section{Firth's penalized-likelihood logistic regression ${ }^{1}$}

\begin{tabular}{llllll}
\hline Predictor variable & Estimate & Lower 95\% & $\begin{array}{l}\text { Upper 95\% } \\
\text { CI }\end{array}$ & $\begin{array}{l}\text { Chi- } \\
\text { squared }\end{array}$ & $p$ \\
\hline Intercept & 1.21 & -0.59 & 3.99 & 1.7 & 0.19 \\
Necrophila americana & -0.98 & -4.68 & -0.37 & 24.8 & $<0.0001$ \\
Nicrophorus pustulatus & 4.20 & 1.50 & 12.63 & 17.8 & $<0.0001$ \\
Nicrophorus orbicollis & -0.32 & -1.15 & 0.01 & 3.5 & 0.06 \\
\hline
\end{tabular}

1 implemented because of perfect separation

${ }^{2} \mathrm{CI}=$ confidence interval 